\title{
The Training Concept at GSOC: Preparation for a Variety of Missions
}

\author{
Daniela Hock ${ }^{1}$ and Michael Schmidhuber ${ }^{2}$ \\ German Space Operations Center, DLR Oberpfaffenhofen, Germany
}

\begin{abstract}
The German Space Operations Center (GSOC) has a 40-year history of space operations in a large variety of missions which cover satellite missions like TerraSAR-X and GRACE, and a human spaceflight mission, Columbus. As training needs differ related to the mission characteristics different approaches have been established. Additionally GSOC is offering operations training to external customers. This paper gives an overview of these activities and the measures taken to unify the training processes.
\end{abstract}

$\begin{array}{ll} & \\ \text { CORB } & =\text { Columbus Operations Readiness Board } \\ E S & =\text { European Simulation } \\ \text { FCT } & =\text { Flight Control Team } \\ \text { ICE } & =\text { Inter Console Exercise } \\ J M S T & =\text { Joint Multi Segment Training } \\ O J T & =\text { On the Job Training } \\ S M E & =\text { Subsystem Matter Expertise } \\ S O C & =\end{array}$

\section{Introduction}

G SOC has been into space operations for more than 40 years and has gained and established considerable working experience in a large variety of missions. In the pioneering days, training was done on the job and simulation campaigns were the usual ways of ensuring the transfer of knowledge and proficiency to new staff members. Documentation about training was scarce and mostly limited to participation lists. This approach worked in the situation of missions with long preparation phases and an abundance of personnel. This situation has nowadays changed in that cost considerations limit the time and the staffing available. Also the rise of quality management has increased the demand for formal control over personnel qualifications.

Formal training became a major topic during the preparation of the Columbus project and it gained even more importance since Columbus became operational on a 24/7 basis since February 2008. The size of the Flight Control Team for Columbus demanded to cope with personnel fluctuations as well as the 24/7 staffing in three 8-hours shifts that required an elaborated training. To achieve good training results, a qualification scheme was developed which consists currently of 4 training blocks, each of them one week in length, simulations and "on the job training". In addition the training has to be interleaved with the external training requirements by ESA and with the international ISS training activities. To support training, training rooms for theory and on-console training and a simulator were set up. The training unit, consisting of 4 persons, has supported the team build-up phase and is now in a routine working phase. Currently on average 24 new Flight Controllers for Columbus are supported during their training phase.

The increased requirements in terms of mission availability in commercial projects like TerraSAR-X have lead to the decision to also establish a formal training and certifications scheme for satellite operations. The main difference to Columbus is that most satellite projects have a completely different approach concerning staffing, external participation and previous experience. So it became important to organize the training in campaigns rather than following a fixed curriculum. Nevertheless a uniform process was established that covers all personnel being involved in control room activities.

\footnotetext{
${ }^{1} 82230$ Wessling, Germany; daniela.hock@dlr.de

282230 Wessling, Germany; michael.schmidhuber@dlr.de
}

\section{1}

Space Ops 2010, 2010-2222 
In addition, GSOC is also offering training for external participants. Now in its tenth year the GSOC Spacecraft Operations Course has attracted nearly 200 persons from various parts of the business. They are introduced to the tasks of the engineering and operations staff. The theoretical lectures are supported by practical lessons where the participants can perform operations activities in a simulation environment.

In 2009 GSOC has cooperated with the Technical University of Munich and provided a practical course for aerospace students. Following partly along the lines of the Spacecraft Operations Course, the students were introduced to the workplace and the tasks of a full-spectrum space operations center. In several tutorials they learned about on-console operations, flight dynamics services and mission planning activities. Being successful and well received, it is planned to repeat this course each year.

\section{Training Concept for the Columbus Flight Control Team}

The setup of the Columbus Mission differs from a satellite mission in several ways. First of all the module Columbus is a manned vehicle attached to the ISS with the possibility of running experiments inside and outside of the habitable volume. Another difference between the Columbus module and a satellite mission is the handling of the real time operations concept. Instead of having flight controllers which are well trained in every subsystem to an equally detailed amount of knowledge, it was decided to have six subsystem positions who have an equally high amount of subsystem overview knowledge, but each and every one of them is only a specialist in their own subsystem. These positions are Columbus Flight Director (COL FD), Columbus Operations Coordinator (COL OC), Columbus Data Management System and Communications System (DMS/COMMS), Columbus Systems Engineer (COL SYSTEMS), Columbus On-orbit Stowage and Maintenance Officer (COSMO), and European Communicator (EUROCOM). As a result, Columbus is operated by specialist teams within the Columbus Flight Control Team (FCT), which handle both the shift work as well as the offline work. Shifts at Col-CC are set up in 8 hours long, 3 shifts per day, 365 days a year, which is another consequence of Columbus being an attached module to the ISS.

\section{A. Facts and Repetition}

Ever since the launch of Columbus, on 7th of February 2008, the Columbus Control Center in Oberpfaffenhofen near Munich has been staffed 24/7 by the four main positions (COL FD, COL OC, DMS/COMMS, COL SYSTEMS). During real time operations these four positions are augmented by the support teams. Several supporting teams exist in the Columbus program: the Engineering Support Team (EST), the European Planning Team (EPT), the User Support Operations Centers (USOC), the EUROCOM and Biomedical Engineers (BME). Only the EPT is located at GSOC, whereas the others are spread all across Europe. The supporting teams are usually staffed 8 hours a day and 5 days a week with few exceptions. The EUROCOM usually support real time operations during the time period when the crew are awake from Cologne, Germany, but when very important or special activities are executed by astronauts in Columbus, EUROCOM will support operations from Col-CC. The EPT in general tries to avoid scheduling activities which need EST and/or USOCs support at the weekend, but in case it is not possible the appropriate teams will be on console giving real time support at weekends as well. Nine different USOC, located in Spain, France, Italy, Netherlands, Norway, Denmark, Germany and Belgium, are responsible for commanding and monitoring their payloads inside Columbus and take care of analyzing the telemetry. The EST is split into an onsite and an offsite Engineering Team. The onsite Engineering Team is located in Col-CC to support real time operations from consoles in so called user rooms. The offsite Engineering Team located in Bremen and Turin supports writing procedures, takes care of investigations into failures and supports the onsite EST on console. This truly international team is banded together by using English as common language.

\section{B. Training at Col-CC}

At the beginning of 2002, the development of a training flow and lesson material started. Since 2004 the four instructors for the Columbus Control Team established an initial training plan which was finalized in late 2009. The current training plan setup only describes the training of the following FCT positions: COL FD, EUROCOM, DMS/COMMS, COL SYSTEMS, COL OC and COSMO. All the other supporting teams, like USOC, EST, EPT and ESA BME, developed their own training flow, which may or may not include some of the elements of the ColCC FCT training flow.

\section{Certification Flow}

The certification flow (see figure 1 "Certification flow of a Columbus Flight Control Team member") for a flight controller candidate is split into different segments. The first big section is build up by the Core Training Blocks consisting of four one week long training events. In these four separate weeks the new flight controller is taught 
what a general FCT member on console needs to know, therefore it is called "Core". A few examples are the handling of the console, speaking over the voice loops and using the voice conference system, using the monitoring control system for observing their subsystem specific telemetry and sending commands as well as introduction to operations documents, the planning processes at Col-CC and NASA, and NASA specific processes and tools. Moreover, the candidate will learn how the operations concept was set up for Col-CC as well as for the other Mission Control Centers and how to react in case a caution, warning or emergency happens on board Columbus. In summary, during these core blocks a beginner learns how to support nominal and off-nominal operations in real time.

After the first Core Training Block, the trainee attends the Columbus User Level, which introduces the subsystems of Columbus: the Thermal Control System (TCS), Environmental Control and Live Support System (ECLSS), Electrical Power Distribution System (EPDS), Data Management System (DMS), and the Communication System (COMMS). Block 2 focuses primarily on introducing and getting hands on the Monitoring Control System and SATMON. These are tools used on console for sending commands and monitoring the telemetry of Columbus.

After Block 2 the candidate has the possibility to take part in Inter Console Exercises (ICE). During these ICEs the candidate can run procedures or practice working on the console, while a simulator in Col-CC is connected to the simulation control room and delivers simulated real time data to the consoles.

In Block 3 the focus is mainly on cautions and warnings as well as on anomaly reporting and response. During this week the candidate learns how to react in off-nominal situations and how to report problems. The next step to take is the Advanced Payload Course. This training class focuses on the functionality of the Payloads inside Columbus. After the candidate has participated in all these classes and passed all the related tests, the candidate's knowledge is reviewed by a Flight Director, an Instructor and the candidate's mentor in the Columbus Operations Readiness Board (CORB). This is a verification step to asses whether the candidate is ready to participate in European Simulations (ES). During these simulations, the trainee is confronted with nominal and off-nominal operational situations and will typically participate in 6-10 as part of the training flow. In parallel with ESs, the candidates also attend Block 4. This includes on-board emergencies and a medical introduction from the crew surgeons from Cologne.

Following Block 4 the candidate must pass their evaluation simulation; in this the candidates are evaluated on their subsystem console performance and subsystem knowledge. Once passed, the candidate is allowed to go into Joint Multi Segment Training (JMST) simulations which are led by NASA, with participation from JAXA FCT and ATV-CC FCT. In addition to this structured flow, candidates must also complete a series of lessons from NASA Flight Operations Training Academy. These are lessons which are provided as online video lessons to familiarize the candidate with the ISS systems. COL FD candidates must also attend two other classes: Safety Training and Human Behavior Performance. Once the candidate is thought to be ready to support real-time operations a second CORB will be scheduled as a final check of operations readiness. Following this, the candidate is certified by the ESA Ground Support Personal Control Board (GSPCB). Throughout the training period the candidate must also perform active or passive On the Job Training (OJT) in which the candidates follow real-time operations together with a fully certified flight controller of their subsystem. In a passive OJT the candidate just observes real-time operations without supporting or running operations. In active OJTs the candidate takes over certain tasks from the fully certified flight controller in order to support real-time operations and to get used to the work on console.

The other big part of a candidates training life is the Subsystem Matter Expertise (SME) Training. The candidates are introduced to their subsystems during the Columbus User Level in Cologne, but to deepen the knowledge on their specific subsystems, additional studies need to occur on their way of becoming a fully certified flight controller. This part is completely done in self study with support from a mentor. The subsystem mentors are responsible for providing help and monitoring the candidates progress. Shortly before the candidate is certified, an OJT in JSC (Houston) or POIC (Payload Operations Integration Center; Huntsville) takes place.

\section{Training Teams and Locations}

The different parts of the training are given by a variety of different training teams at different locations. The instructors at Col-CC in Munich are responsible for the Core Training, the FOTA self study and the ICEs. The subsystem mentor at Col-CC is responsible for SME knowledge and OJTs. The simulation officers at Col-CC coordinate the ESs and the JMSTs. At the EAC in Cologne the candidates attend the Columbus User Level, the Payload Advanced Course, the Safety Training and the Human Behavior Performance Training. The Training Control Board (TCB), the Ground Support Personal Control Board (GSPCB) and the Evaluation Simulations are established at EAC as well. 


\section{E. Concept of Block Training}

In order to achieve a good "product", namely a competent flight controller, several main concepts have been developed. One of the golden rules is "hands on". Whenever it is feasible, the candidates are taken down to the control rooms or sit in front of a laptop to make sure that the presented material has not only been seen but also has been "touched". The second concept is teaching in small groups. It is preferred to teach in the situation of one instructor and one to two students instead of giving the lesson to the whole group of 10-12 people. The lesson objectives bring the understanding of processes or operational concepts to the foreground and secondly focus for example on the introduction of tools. Another very important rule is fulfilled during the development phase of a lesson, in which an instructor learns first from an expert, who might either be a flight controller, an engineering team member or a software developer. Together with the expert the completed lesson material is checked. Furthermore, guest instructors are invited to teach during the core training. And a last but not minor important point in the training concept is that all of the instructors are already or become fully certified flight controllers in the different subsystems, to have better insight into real time operations and to support the trainees even better during their certification period.

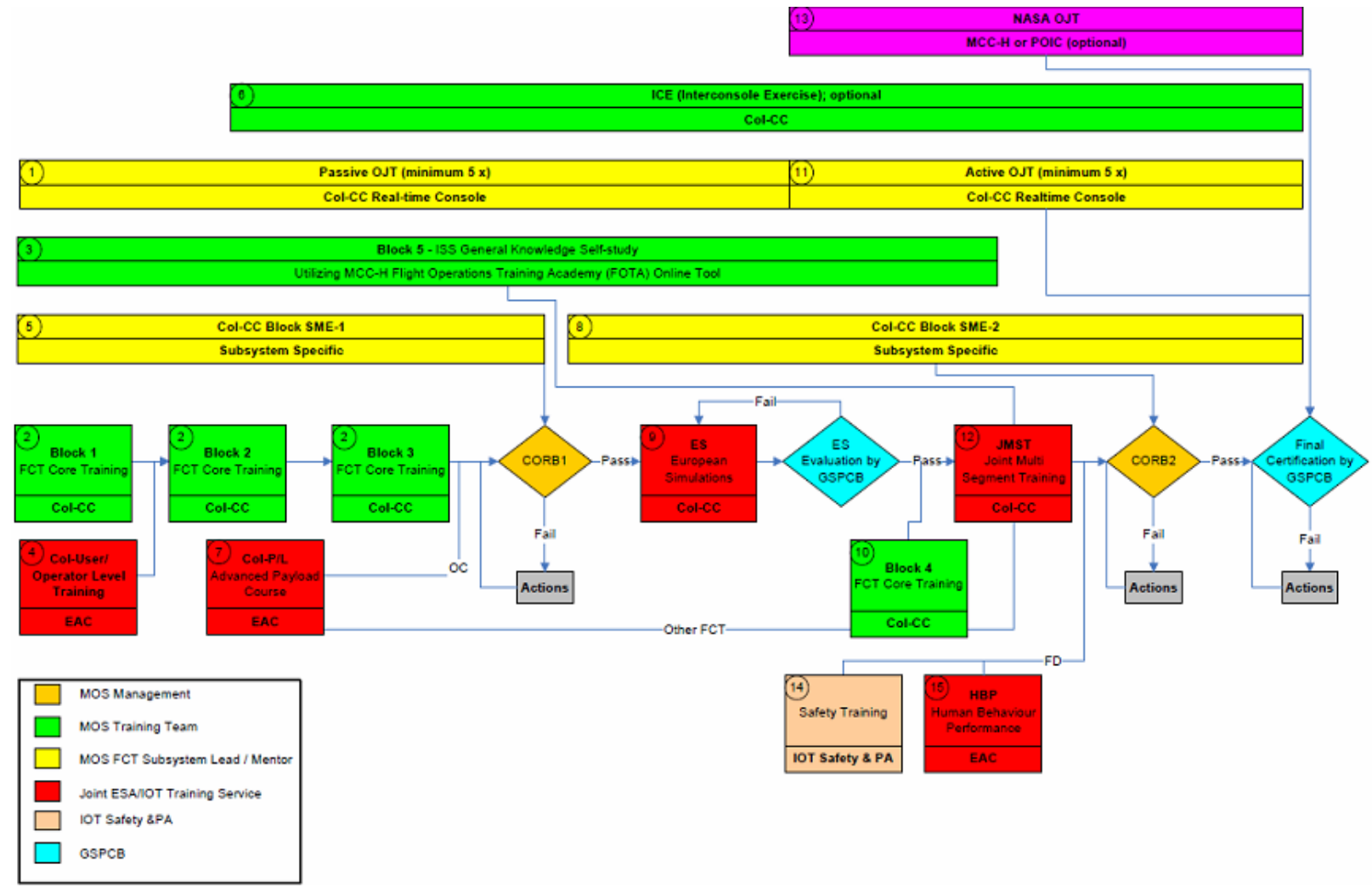

Figure 1: Certification flow of a Columbus Flight Control Team member

\section{F. Progress between 2008 and 2010}

In the last two years, the team has established a routine Core Block Training flow which certifies new flight controllers in 9-12 months. Two semesters of new flight controller are going through the core training each year, which leads to an average of 24 certified flight controllers per year. This routine has been achieved by streamlining the training concept and the lesson updates. Lesson material is now more stable and, once produced, requires only small updates or adjustments to new documents. This takes a lot less time than developing new lessons and allows the team of four people to cross-teach. Every instructor is in principle able to teach a lesson even if it was prepared by another instructor. Another step forward was the creation of ICEs in which - as described above - the candidates have the possibility to study their subsystem with the help of an instructor. A big achievement in 2009 was the introduction of the Columbus Operations Readiness Boards. 


\section{G. Future Intentions}

One of the future aims is that all instructors become certified flight controllers, and work on console for 20-30\% of their time. Another goal is to involve the Columbus Operations Support Teams more in Columbus Core Training. An already ongoing project is the development of a candidate mentoring program. Once the instructors are certified, they become the main point of contact for all training and subsystem related questions. This will have the big advantage that the student is led through the training flow by one person who knows the knowledge level of the trainee. This will ensure that the candidate is supported in the best way throughout the training flow. Another currently ongoing project is the development of a centralized SME catalogue for each subsystem. This shall ensure that all the important subsystem related topics are covered in an order that matches the needs of the Core Training Blocks and on console training. In support of this, the OJT concept is going to be changed. To make sure that every important activity was at least seen once by the candidate, objective oriented OJTs are going to be developed.

\section{Training Concept for Satellite Operations}

\section{A. Internal Staff Training}

As pointed out in chapter I, satellite operations were traditionally more campaign oriented. A mission system was constructed and a complete team trained together for the singular event of a LEOP. During tests and simulations the staff was becoming familiar with and proficient on their own system.

With the beginning of the routine operations phase of TerraSAR-X the idea of formalized training for satellite operations came up. At that time, project Columbus already had its full-scale training and certifications program established. While obviously having an overlap in many aspects, the field of satellite operations has its own heritage and some different requirements. The very specific training plan, the complex interweavement with other agencies and the high work load of the Columbus training group led to the decision to establish a separate training scheme for satellite missions.

The newly created SATOPS training scheme contains all the elements of training that missions at GSOC typically come across. It leaves room for adaptations and waivers. Participants receive a certificate of their tests. The certificates expire after a certain interval. They are only renewed if a new test is passed or equivalent qualification can be provided. There is no external certification agency involved. All training participations, test results and certifications are kept in a central database.

An exception is the multimission and other command operations staff. These services are typically provided by contractor companies. They have their own training and certification scheme. The training plans and the passed certificates are coordinated with and accepted by GSOC.

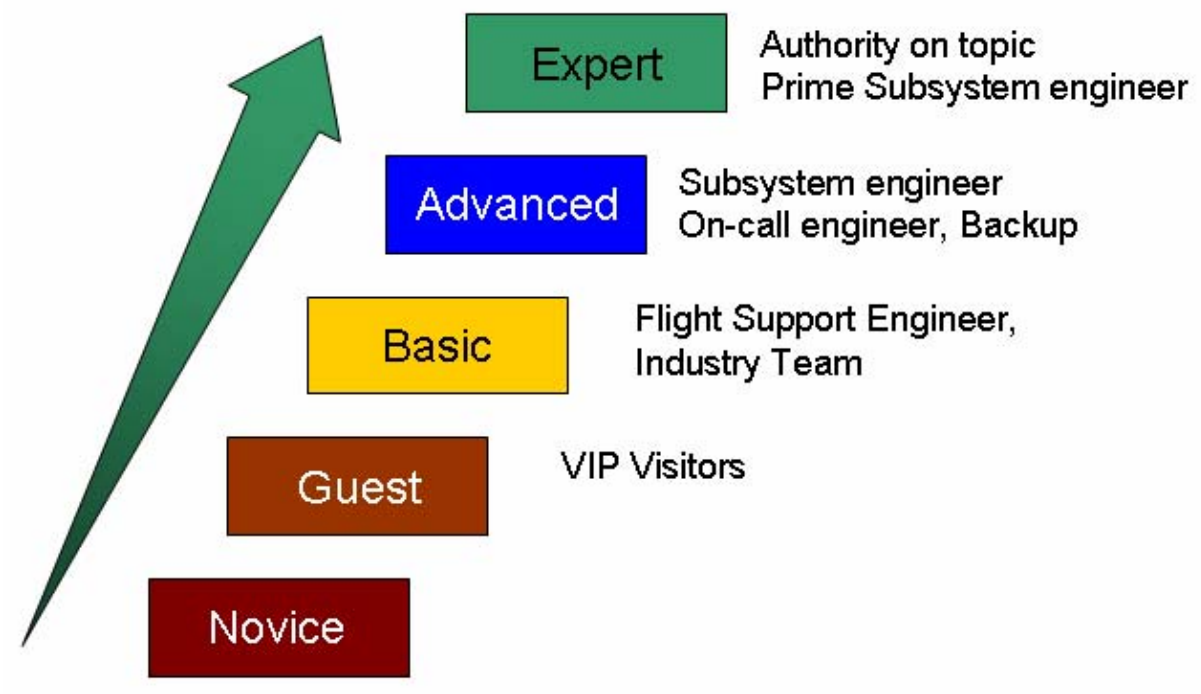

Figure 2: The level of proficiency that control room privileges are based upon 


\section{Proficiency and Privileges}

The basic idea is to provide and ensure adequate qualification for anyone who is involved in or present during operations in the control room. Personnel are divided into five levels of proficiency starting from the novice who is not allowed to perform any action or even be present in the control room without supervision. The level of proficiency is not a stand-alone qualification in itself. For each type of function and each project a different level may be held by any person. Some levels are acquired implicitly with other functions or projects, other transitions must explicitly be gained.

For example a subsystem engineer for project $A$, automatically has guest status for any other project at GSOC. However to be a Flight Support Engineer in project B he or she has to pass a cross-training.

Table 1: Control Room Privileges

\begin{tabular}{|l|l|l|l|l|l|}
\hline \multicolumn{1}{|c|}{ Level } & Novice & Guest & Basic & Advanced & Expert \\
\hline Entrance & No & Yes & Yes & Yes & Yes \\
\hline Monitoring & No & No & Yes & Yes & Yes \\
\hline On Call & No & No & No & Yes & Yes \\
\hline Position & No & No & No & Yes & Yes \\
\hline Position Lead & No & No & No & No & Yes \\
\hline
\end{tabular}

\section{Skills, Lessons}

Each qualification step is assembled from a pool of skills and lessons that is tailored to the project specific needs. Typically e.g. "Basic" proficiency will include training on the voice intercom and the telemetry monitoring systems, as well as a basic subsystem and system knowledge. Note that there are no lessons and skills available that bring a person to expert level. Expert level is reached by nomination from the project manager typically after work in several projects and at an early stage in a project.

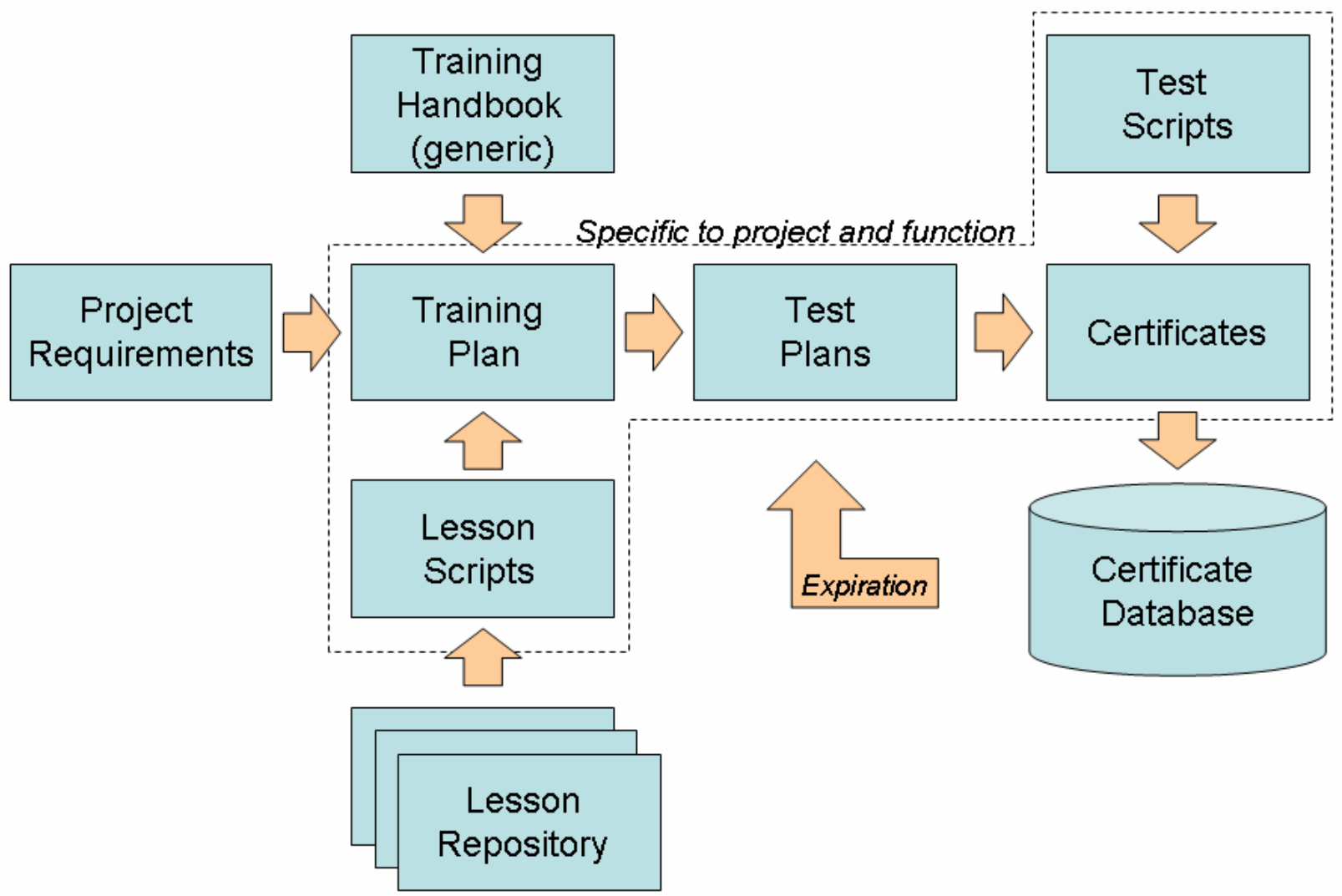

Figure 3: The flow of documentation and information for training 


\section{Tests and Waivers}

Different ways of demonstrating proficiency in a skill are possible. It may be a written test, participation in a simulation campaign, and proof of application within a certain time period (for recertification) or any combination. Especially important are waivers that can be accepted by project management instead. This would be the case for staff with long-proven experience.

\section{Example Training Campaigns}

The first case of applying this new training scheme was the establishment of an extended on-call engineering team for the TerraSAR-X mission. A detailed paper on this topic ${ }^{2}$ is presented in this SpaceOPS conference. Here it was necessary to certify a pool of engineers on the subsystems of the TerraSAR-X spacecraft in order to provide oncall support. Unlike in previous missions and unlike in the early phase of TerraSAR-X it was decided to upgrade the support to encompass a complete team of flight director and all subsystem engineers in order to minimize interruption of service. Four persons shall be available at any time to cope with unforeseen situations. They are rotating in four shifts resulting in the need for 16 persons. TerraSAR-X is in the comfortable situation that a sister project with a near-identical spacecraft is in preparation (TanDEM-X). Therefore a complete engineering team is in place. The training plan was that the existing subsystem and system engineers compile a set of documentation and skills that are required to do the on-call tasks. During a period of several months with study of documentation, participation in the TanDEM-X mission rehearsals and inclusion in TanDEM-X mission preparation the candidates are coached by the subsystem experts. Written tests were created, whose questions are typical for on-call situations. Compulsory are also the successful passing of an unprepared simulated on-call alert test. After the TanDEM-X launch and if operations are smoothly ongoing, there will be periodical on-call rehearsals in order to qualify for recertification each year.

\section{Next Steps}

The next step of establishing formalized training will be the introduction of a basic space operations training. This shall provide a common knowledge base for all projects. In the first months of their time at GSOC, newcomers will be passing through a sequence of lessons. Up to now the following topics have been identified as suitable: Voice system and protocol training, basic subsystem knowledge, tools training on monitoring and control systems, participation in simulation, as well as the content of the Spacecraft Operations Course (cf. below). It is obvious that no further unification across all projects seems to be possible due to diverging mission characteristics.

\section{B. Training for external participants}

GSOC has a history of being a spreader of knowledge. Establishing and setup of ground systems and consultancy for institutions in Germany and other countries was always an essential part of its business and selfunderstanding. The intention for taking the effort and offer the course lies in the claim of GSOC to present itself as an established bearer of operations know-how and a public fosterer of the space industry. As the business is expanding, the spreading of operations know-how is necessary and inevitable. By offering training, the initiative and momentum is on GSOC's side. This serves also the purpose of spreading a uniform approach to operations in the industry. As GSOC has a huge variety of mission types in its portfolio, it is able to provide training in almost all areas of operations.

\section{Spacecraft Operations Course}

GSOC is offering a general operations training for external participants. Now in its eleventh year the GSOC Spacecraft Operations Course has attracted around 200 persons from various parts of the business. They are introduced to the tasks of the engineering and operations staff. The theoretical lectures are supported by practical lessons where the participants can perform operations activities in a realistic simulation environment.

No restrictions or selections of the audience are made by GSOC. Participation is open to anyone, but the number of participants is normally limited to 18. Experience shows that a huge variety of persons are attracted. Students and job beginners for job field demonstration, professionals from engineering and management for comparing work places and procedures, insurance personnel for better understanding of the matter, first-time satellite owners also for understanding, to point out a few.

The duration of the course is five days including arrival and departure. Three different types of sessions are on the agenda. Site tours show the facilities of the control center at Oberpfaffenhofen and the ground station at Weilheim. Main part is the 20 lectures of 30-60 minute duration about diverse project management and satellite operations topics. They are complemented by three practical exercises where attendants receive a hands-on lesson about mission planning, flight dynamics and mission operations. As the practical parts are a more intensive training the participants are divided into three teams of six persons that are rotating shifts. 
All lessons and exercises were designed and are given by project personnel. This serves the purpose to transport control room credibility. This system is rewarded when participants ask questions. The answers are always in direct relation to reality. Numerous examples and anecdotes can be cited by teachers from their experience on many matters. Their elation for the subject makes is easier for the audience to follow matters that might otherwise be hard to follow in the dense agenda.

From the beginning external contributions were included. There is an exchange agreement with the University of Southampton. GSOC supplies an overview mission operations lecture to their Spacecraft Systems Engineering Course in exchange for two Space Environment and Satellite Design lectures. The two courses are supplementing each other. The cooperation scheme has recently been expanded. Since 2009 there are also contributions by ESOC and CNES about ATV and interplanetary operations. Those aspects are not within the portfolio of GSOC and are therefore rounding off the course perfectly.

The course has received a good reputation all over the trade of spacecraft operations. It has been high in demand and typically a handful of applicants had to be turned down each year for number limitation. The course documentation itself has internally become a source of reference for other training activities. GSOC itself is bringing in their own beginners as "back-seaters" to give them a starter into their careers. Other centers and industry are recommending the GSOC course to their own beginners.

\begin{tabular}{|c|c|c|c|c|}
\hline Monday & Tuesday & Wednesday & Thursday & Friday \\
\hline & & Bus transfer $O P$->> WHM & & \\
\hline & $\begin{array}{l}\text { 9:00 - 9:45 } \\
\text { Project } \\
\text { Management }\end{array}$ & $\begin{array}{c}\text { 9:00 - 9:30 } \\
\text { Ground Station } \\
\text { Design \& Ops. }\end{array}$ & $\begin{array}{c}\text { 9:00 - 10:00 } \\
\text { TCR/DH Ops. } \\
\text { Payload Operations }\end{array}$ & $\begin{array}{c}\text { 9:00 - 9:45 } \\
\text { PoweriThermal } \\
\text { Subsystem Ops. }\end{array}$ \\
\hline $\begin{array}{c}\text { 10:00 - 10:45 } \\
\text { Arrival /Registration }\end{array}$ & $\begin{array}{c}\text { 10:00 - 11:00 } \\
\text { Introduction } \\
\text { Mission Operations }\end{array}$ & \multirow{2}{*}{$\begin{array}{l}9: 30-11: 30 \\
\text { Tour at Weilheim } \\
\text { Grd. Station }\end{array}$} & $\begin{array}{c}\text { 10:15 - } 11: 15 \\
\text { Attitude } \\
\text { Dynamics }\end{array}$ & $\begin{array}{c}\text { 10:00 - } 11: 00 \\
\text { AOCS } \\
\text { Operations }\end{array}$ \\
\hline $\begin{array}{l}\text { 11:00 - 12:15 } \\
\text { Introduction }\end{array}$ & $\begin{array}{c}11: 15-12: 15 \\
\text { Mission Operations } \\
\text { Preparation }\end{array}$ & & $\begin{array}{c}\text { 11:30 - 12:15 } \\
\text { Propulsion } \\
\text { Subsystem Ops. }\end{array}$ & $\begin{array}{c}11: 15-12: 15 \\
\text { Interplanetary Operations } \\
\text { (ESOC) }\end{array}$ \\
\hline $\begin{array}{l}\text { 12:15 - } 13: 30 \\
\text { Lunch }\end{array}$ & $\begin{array}{l}\text { 12:15 - 13:30 } \\
\text { Lunch }\end{array}$ & $\begin{array}{c}\text { Bus transfer WHM }->O P \\
\text { Lunch }\end{array}$ & $\begin{array}{l}\text { 12:15 - } 13: 30 \\
\text { Lunch }\end{array}$ & $\begin{array}{l}\text { 12:15 - 13:30 } \\
\text { Lunch }\end{array}$ \\
\hline $\begin{array}{c}13: 45-14: 30 \\
\text { Space Environment } \\
\text { (Univ. Southampton) }\end{array}$ & $\begin{array}{c}\text { 13:45 - 14:45 } \\
\text { Mission } \\
\text { Planning } \\
\end{array}$ & $\begin{array}{c}13: 45-15: 00 \\
\text { GSN \& Control Center } \\
\text { Design \& Ops. }\end{array}$ & $\begin{array}{c}13: 45-14: 45 \\
\text { ATV Operations (CNES) }\end{array}$ & $\begin{array}{l}\text { 13:45 - 14:30 } \\
\text { Flight Experience }\end{array}$ \\
\hline $\begin{array}{c}14: 45-15: 30 \\
\text { Satellite Design } \\
\text { (Univ. Southampton) }\end{array}$ & $\begin{array}{c}15: 00-16: 00 \\
\text { Flight Dynamics } \\
\text { Operations }\end{array}$ & $\begin{array}{c}15: 15-16: 00 \\
\text { Mission Operations } \\
\text { Execution }\end{array}$ & $\begin{array}{c}\text { 15:00 - 16:00 } \\
\text { ISS } \\
\text { Operations }\end{array}$ & $\begin{array}{c}\text { 14:30 - 15:00 } \\
\text { Closing Remarks }\end{array}$ \\
\hline $\begin{array}{c}15: 45-16: 45 \\
\text { Tour at O'hofen } \\
\text { Control Center }\end{array}$ & $\begin{array}{c}\text { 16:15-17:30 } \\
\text { Control Room } \\
\text { On Console Training }\end{array}$ & $\begin{array}{c}16: 15-17: 30 \\
\text { Mission Planning On } \\
\text { Console Training }\end{array}$ & $\begin{array}{c}16: 15-17: 30 \\
\text { Flight Dynamics } \\
\text { On Console Training }\end{array}$ & \\
\hline $\begin{array}{c}\text { 16:45 - } 18: 00 \\
\text { On Console Training } \\
\text { Introduction }\end{array}$ & & & & \\
\hline
\end{tabular}

Figure 4: The agenda of the 2009 Spacecraft Operations Course

\section{University Training Cooperation}

GSOC has found that usually university graduates from space engineering have only a vague idea of the challenges and rewards of the space operation business. Typically standard university courses are concentrated around engineering and mission analysis aspects. The idea came up to establish cooperation with university to counter this effect. The Institute of Astronautics of the Technical University of Munich (TUM) already offered a practical course of work experience since many years. It was commonly decided to use this platform for a space operations variant at the control center. Two goals are set: fostering the awareness of students about aspects of space operation and to establish the idea of GSOC as a potential workplace.

For the first time in 2009, GSOC has cooperated with the TUM and provided a practical course for aerospace students. Following partly along the lines of the Spacecraft Operations Course, the students were introduced to the 
workplace and the tasks of a full-spectrum space operations center. In several tutorials they learned about on-console operations, flight dynamics services and mission planning activities.

The students are supervised by a representative from the university. They are prepared for the course by a number of theoretical lessons on the campus, where they are also given a spanning task that has to be worked out until the end of the course. A concept for a mission operations scenario has to be found by the students in working groups. The course is embedded in the curriculum and a final presentation has to be given. Highlights of the course are the voice training given by the Columbus training group and the on-console training done with an advanced spacecraft simulator.

Being successful and well received, it is planned to repeat this course each year. The preparations for 2010 are already done and we expect the students from mid may on for one afternoon each week of the summer semester.

\section{Training for Customers}

As spaceborne applications are spreading and more wide-spread, many new customers and users have to face the task of gaining detailed knowledge about spacecraft operations. An ideal starting point is the Spacecraft Operations Course described above. After that however, several customers decided to book a more dedicated training for their engineering or administrative personnel. These trainings are custom-tailored. Typically the duration is two or three sessions of one week each with pauses of several weeks in between. The topics covered in these courses are ranging from again introduction to spacecraft systems to detailed lectures about space engineering topics and operations to mission specific lessons. Among the specialties that GSOC can offer are Flight Dynamics and Mission Planning where unique expertise is available. A special case is the training offered in conjunction with software packages provided by GSOC, e.g. flight dynamics software or spacecraft database editors.

\section{Common Ground}

The two training units described above currently exist in parallel within GSOC. To minimize potential duplications of material and expertise, the training responsibles are working in cooperation. Most prominent example up to now is the common Voice Intercom System and Procedures Training. The relevant Columbus lesson can easily be adapted to satellite missions.

While in principle aiming for more cooperation and integration, this is limited by the diverging characteristics of the different missions. For the same reason the potential for common training between satellite projects is also limited to the basic level.

The Columbus Project has three control rooms available for supporting real-time operations and training. The practical parts of the lessons as well as ICEs and simulations, but except OJTs, are done in the training control room. In addition a classroom with a seat capacity for 14 flight controller candidates can be used for theoretical training lessons and presentations. Only this room can be shared with satellite training due to security restrictions on access.

While satellite projects also typically use their own control rooms for training, external trainings have to be arranged with the ongoing projects. Typically this leads to a rotating use of different rooms. As projects are now closely following each other and there is a tendency to longer duration use, it becomes increasingly harder to find a suitable room for external training. GSOC is considering to establish an additional, dedicated training facility.

\section{Conclusion}

The different concepts of training for a variety of missions at GSOC were presented. It was shown that with increasing demand on staffing and availability and shorter preparation times it becomes necessary to formalize and streamline training. The training and certification profiles differ for continuous, routine service type missions, like Columbus, compared to campaign oriented, exploration type missions, like scientific satellite missions. Two training entities were established at GSOC. Cooperation is possible to a limited degree. Both entities succeeded in setting up a successful training concept over the last years.

\section{References}

${ }^{1}$ B. von Kuhlmann, "How to become a certified well trained Flight Controller in ESA Manned Space Flight," SpaceOPS conference 2008, paper 2008-3486

${ }^{2}$ A. Codazzi, "Extended On-Call Support for TerraSAR-X: Minimizing Payload Outages“, SpaceOPS conference 2010, paper 2010-2163

${ }^{3}$ Col Flight Control Team Training and Qualification Plan (OPS-PL-1TRG-613-GSOC), DLR \& EADS Astrium, 2nd ed., 31st of September 2009

${ }^{4}$ The GSOC Spacecraft Operations Course http://www.dlr.de/rb/desktopdefault.aspx/tabid-2709/4133_read-6370/ 